\title{
Knowledge Management System: Critical Success Factors and Weight Scoring Model of the Technical Dimensions
}

\author{
Mounir M. El Khatib \\ Assistant Professor: \\ Hamdan Bin Mohammed Smart University \\ Dubai, UAE
}

\begin{abstract}
Knowledge Management System is an old topic implemented since 1996 in different industries, however, it is still considered new and young in some regions such as the Middle East. Few of the UAE organizations have proven that the effective implementation of KM initiative adds valued to them in terms of cost reduction and time reduction. These are organizations such as Dubai courts, Dubai police, Dubai Customs and Emirates Airline.

The purpose of this research is to study and identify the technical dimension critical success factors of $\mathrm{KM}$ and then use lessons learned to develop a weight scoring model as a framework to be used in other UAE organizations. A survey and interviews were conducted to answer research hypothesis.

The findings revealed that CSFs prioritization depends on the organization's strategy and type of business. The services governmental organizations, such as Dubai Customs, Dubai Courts and Emirates Airline emphasized on the software and hardware features in addition to managing and retaining tacit knowledge. Private production organizations, such as BP and ADOG, gave priority to the social networking applications and protocols and standard to manage the flow of data and information and then sustain the quality.
\end{abstract}

\section{Keywords}

Knowledge management, Critical Success Factors, and Weight Scoring Model, Technical Dimensions

\section{INTRODUCTION}

Knowledge Management is relatively a new field of study that has taken both the industry and academia by storm; it has in fact turned into a buzz-word. The discipline is hardly two (2) decades old but has been able to create waves. In the simplest form, knowledge Management is the process of managing the organizational knowledge; it is ongoing and a continuous process that captures, develops, shares and facilitates the better management of knowledge created by the organization [1].

Knowledge is considered as power and the present century has also been coined as the century of knowledge. All great nations are striving to develop a knowledge economy, which proves that knowledge management is vital for organizations too. Access to knowledge at the right time is critical; it can help managers make the right decision promptly and swiftly, especially when there is a lot of unneeded data, or information overload [2]. Studies have shown that companies lose billions of dollars due to lost knowledge. Knowledge management systems aim to capture the knowledge created, not just the explicit knowledge but also the less quantifiable tacit knowledge that can serve as a driver for business [3].
Knowledge Management System has many benefits and is used by almost all industries and segments world-wide covering governmental organizations, private and non-profit ones. Every organization that values time and knowledge and faces competition has to use knowledge management systems.

The importance of knowledge management and associated benefits has been realized by the government of the UAE, and now knowledge management has been incorporated and inculcated in to various functions and processes of the government. It is an objective of the government of Abu Dhabi to become a knowledge management based economy by 2030 and it also firmly believes that knowledge management is a driver for change and competitive advantage. The Government also realizes that without KM. the vision 2030 will not become a reality hence knowledge Management is given the due importance and significance it deserves at all cadres of policy making.

The contemporary knowledge management style in the UAE is not only circumscribed only to the attainment and procurement of new knowledge and applying it to oblige and assist the socio economic goals and objectives; but it also goes in deeper grounds to facilitate and strengthen the capacity building procedures that are the essential building blocks needed to breed and localize knowledge in order to develop an all-inclusive knowledge framework that would empower the UAE to take ownership of knowledge and acclimate and acclimatize it to defy the hurdles in the way of sustainable development. The initiatives and knowledge management programs in the Emirate of Abu Dhabi were based on accurate diagnosis and a thorough reading of potential gaps in the local knowledge landscape, and were also characterized by integrating the three poles of knowledge society: technology, economy and society; hence, their gains and benefits came proportionate with the aspirations of the decision maker, meeting the needs of citizens and residents, and responsive to the requirements of development goals [4].

The Government of the UAE is very fanatical about strategic management. In a comparative study by Accenture it was found that the Government of the UAE's inclination and interest in strategic management and the deployment of various strategic management initiatives with special emphasis on knowledge management is one of the key competitive advantages and also a reason for the phenomenal growth of the nation [5]. The same study ranked UAE as the 3rd best digital government.

\section{LITERATURE REVIEW}

Today, more attention and interest are given to adapting a KM system, especially in the UAE. The main reasons are globalization, competitive environments, trend toward 
knowledge intensive products and services, as well as rapid progress in information technology [6]. Implementing effective KM leads to substantial savings and performance improvements [7]. Hence, it was important to understand the critical success factors of different dimensions of a KM system. Researchers classified KM dimensions into three (3) which are: organizational, human, and technical dimensions [8]. The organizational dimension includes leadership, strategy, and business processes whereas the human dimension includes behavior, working, and learning styles. The technical dimension covers both technology and information elements.

Technology elements are those tools and services which automate the KM system such as software and hardware (quality, language, efficiency, security, connectivity, user friendliness), Business Intelligence application (Expert system, data mining, email agents, and interface agent), database and repositories (data warehouse, web house, reports, lesson learnt, documentation), Operating systems, Browsers, Protocols, Standards, social networking applications, etc [9].

Information elements cover tacit and explicit knowledge [6]. Explicit knowledge is knowledge that can be documented, and stored in the database in terms of manuals and procedures. Tacit knowledge is embedded inside the minds of people and linked to experience and memories and is the most important part of KM where it creates value and then drives competitive advantage. Effective KM is a combination of both explicit and tacit knowledge. [10]. Indeed, the critical role of IT lies in its ability to support collaboration, and search for knowledge [9].

\section{PROBLEM STATEMENT}

Abu Dhabi Oil and Gas (ADOG) is an offshore oil and gas production organization. It produces oil and gas from two (2) fields and transfers the crude through a sophisticated pipeline network to Das Island for processing, storing and exporting. ADOG's long term strategy is to achieve excellence in all aspects of business and sustain superior performance to compete globally. One area of development is knowledge Management (KM). ADOG is planning to develop effective Knowledge Management systems to create, share, and retain knowledge to serve the technical community. ADOG noticed that with the huge flow of new generations of employees to replace the older, expert generation, it might lose one of its core competencies, which is explicit and tacit knowledge. To retain the knowledge within the organization, ADOG should ensure successful implementation of this project. Therefore, it is important to get more insights and identify the technical dimension critical success factors of $\mathrm{KM}$ system. The objective of this study is to identify the technical dimension critical success factors of KM and develop a weight scoring model for assessing the technical dimension.

\section{PROBLEM JUSTIFICATION}

Knowledge management (KM) becomes a necessity for those organizations that want to achieve and sustain superior performance and then compete globally. It drives learning and improvement and then generates significant performance benefits. KM is a power, especially in today's technologically advanced world. Managing organizational knowledge is critical to operate efficiently using essential information and the right people. If the system was not able to add value to the organization and people, it becomes a failure. A KM system helps many inexperienced technical employees to access information and creates a learning environment and then enhances their individual performance as well as business productivity. An organization needs to protect its intellectual property from loss when employees leave or switch jobs. If a KM database is used effectively, it would reduce the gap in knowledge between new and expert employees, mistakes, duplications of effort and would increase the speed of operation [11].

\section{RESEARCH HYPOTHESIS}

The research questions and hypotheses are set to be as follows:

\begin{tabular}{|l|l|}
\hline $\begin{array}{l}\text { Q1: Identify the CSFs of } \\
\text { technical dimensions in } \\
\text { implementing a KM system }\end{array}$ & $\begin{array}{l}\text { H1: The main technical } \\
\text { dimensions in today's } \\
\text { business are software and } \\
\text { hardware features and the } \\
\text { use of latest technology and } \\
\text { applications }\end{array}$ \\
\hline $\begin{array}{l}\text { Q2: Prioritize the CSFs of } \\
\text { technical dimensions in } \\
\text { implementing a KM system }\end{array}$ & $\begin{array}{l}\text { H2: The top CSFs are } \\
\text { management of tacit } \\
\text { knowledge and the use of } \\
\text { social networking } \\
\text { application }\end{array}$ \\
\hline $\begin{array}{l}\text { Q3: Conduct weight } \\
\text { assessment (weight scoring } \\
\text { model) }\end{array}$ & $\begin{array}{l}\text { H3: Weight scoring is } \\
\text { allocated to each factor based } \\
\text { on business requirements and } \\
\text { priorities }\end{array}$ \\
\hline
\end{tabular}

\section{RESEARCH DESIGN AND METHODOLOGY}

\subsection{Overview}

To achieve the research objectives, a deductive research approach was used. The required data and information was gathered from:

- Survey questionnaire: A designed questionnaire was distributed to the selected organizations in order to identify and prioritize technical dimension critical success factors of KM system.

- Interviews: Interviews were conducted with the selected organizations. A quantitative (descriptive) methodology and primary data were utilized in order to explain the findings.

- Case studies: A BP case study was presented to reflect the organization's experience and lessons learned from different organizations.

- Online Resources: These were used as a resource of official studies, articles and magazines on this topic. Internet official websites and videos were used as other sources of information.

The survey consisted of 60 persons from Dubai police, Dubai Court, Dubai Customs and Emirates Airline. Interviews were conducted with the following organizations: Dubai Police, Dubai Courts, Emirates Airline and British Petroleum. 


\section{DATA ANALYSIS AND DISCUSSIONS}

\subsection{Research Findings}

The Survey findings revealed that most of the participants strongly agree on developing robust a KM system in their organizations. See figure 1. Participants justified that Knowledge is one of the main internal capabilities that can be developed and shared to improve the business. A smart and effective system can help in improving new employee knowledge about the business and learning from best practices.

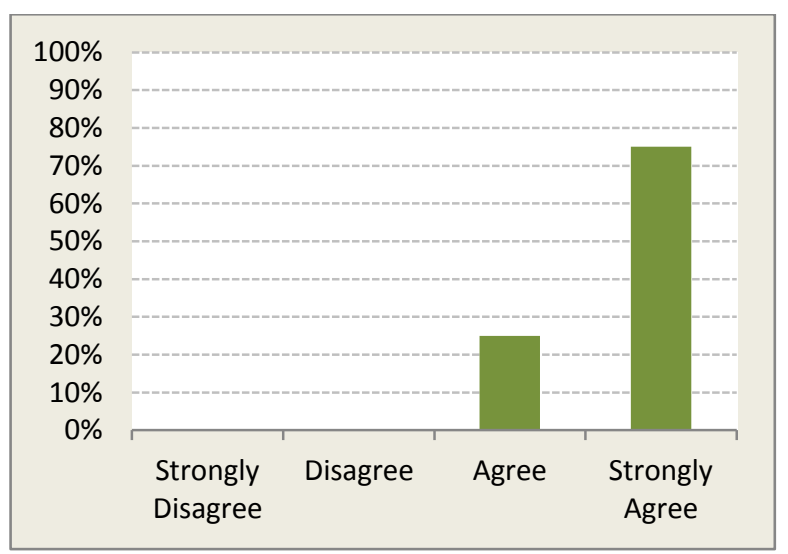

Fig 1: I agree that organizations should have a robust KM system in today's business

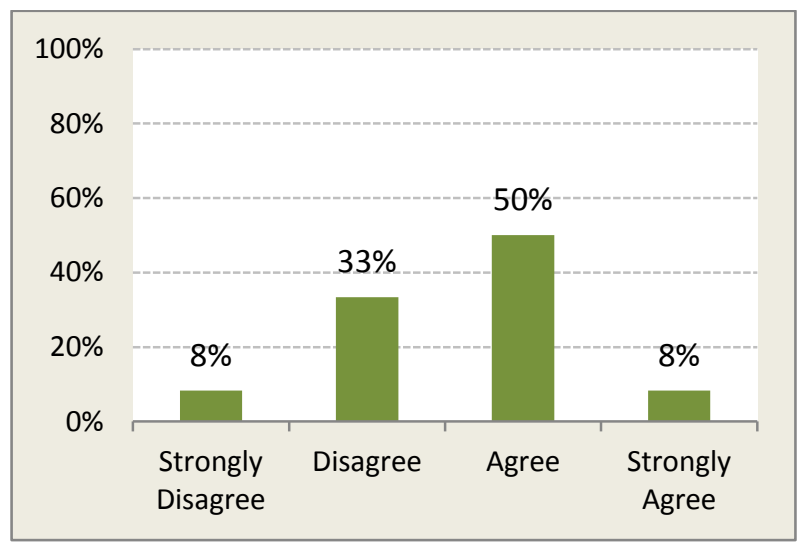

Fig 2: We are benefiting from using our organization's KM system in improving individual \& organizational performance

Although there are several benefits from using a KM system, $42 \%$ of the surveyed population expressed that they are not getting real benefits. See figure 2. The main reason behind this reality is that there is no continuity in developing, updating and sustaining the system. Lack of ownership of the system also impacts negatively on the quality of the full system (AD Company interview, 2014). Best practices show that a KM system requires a dedicated team to manage and control the flow of data and information and sustain its quality. Oil and gas organizations such as BP, Chevron, ExxonMobil, and Schlumberger have dedicated teams as well as virtual teams, and this is a critical success factor ${ }^{[12]}$.

Q1: Identify the CSFs of technical dimensions in implementing a KM system.
H1: The main technical dimensions in today's business are software and hardware features and the use of latest technology and applications.

There are two (2) types of knowledge stored in the system as mentioned before, tacit and explicit. Most of the surveyed organizations highlighted that they are focusing on storing and using explicit knowledge with little attention given to retention of tacit knowledge. See figure 3. Participants identified technical dimension critical success factors as follows:

1. Software and hardware features

2. Availability of business intelligence applications

3. Strong database and reliable repositories

4. Type of operating system

5. Effectiveness of browsers and search engine

6. Protocol and standards in place

7. Usage of customized social networking applications

8. Tacit knowledge management and retention

$77 \%$ of the participants agreed that the main $\mathrm{KM}$ system technical dimensions are software and hardware features, and the use of latest technology and applications. See figure 4. Information technology assumes an essential part in all parts of present day business. The use of hardware and software in business processes is now a part of business ${ }^{[13]}$.

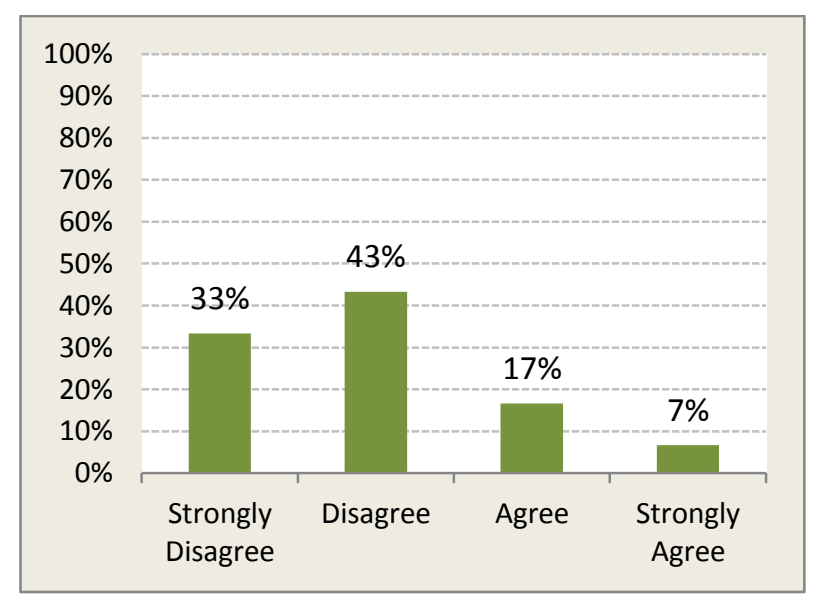

Fig 3: My organization focuses more on tacit knowledge than explicit knowledge 


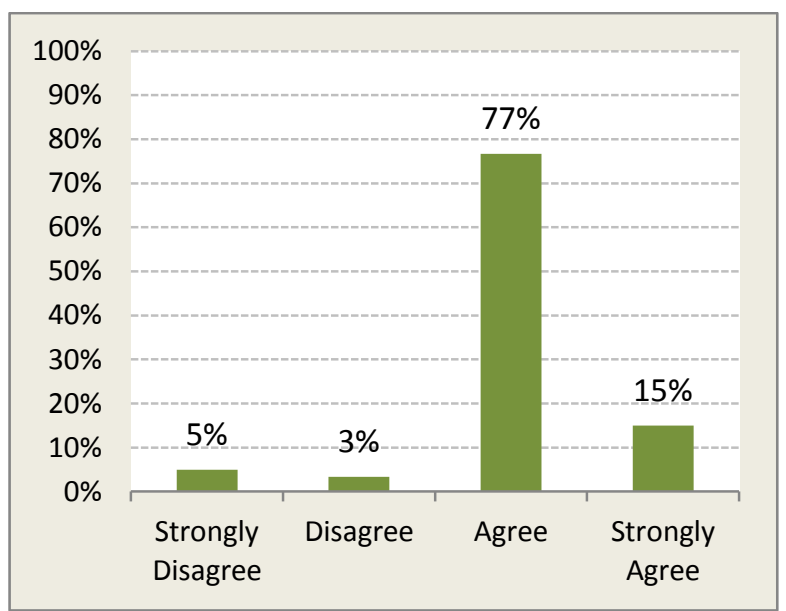

Figure 4: The main technical dimensions in today's business are software and hardware features, and the use of latest technology and applications

Q2: Prioritize the CSFs of technical dimensions in implementing a KM system.

H2: The top CSFs are the management of tacit knowledge and the use of social networking applications.
The participants were asked to prioritize the technical dimension CSFs. The findings are shown in table 1. Different organizations show different priorities. For instance, services governmental organizations, such as Dubai Customs, Dubai Courts, and Emirates Airline focus on software and hardware features in addition to managing and retaining tacit knowledge. Private production organizations such as BP and ADOG gave priority to social networking applications, and protocols and standards, to manage the flow of data and information and then sustain the quality. The prioritization depends on the business strategy and the best practices approach in implementing effective change in their fields.

The private sector production implementation philosophy was the first to create the culture, implement change transformation, and prepare a rich environment before implementing technical solutions. The philosophy of service governmental organizations, on the other hand, is to use best practices, experience, and knowledge to improve and deliver high quality services to customers through effective software and hardware features.

Q3: Conduct weight assessment.

H3: Weight scoring is allocated to each factor based on business requirements and priorities.

Table 1: Technical Dimension Critical Success Factors Prioritization

\begin{tabular}{|c|c|c|c|c|c|c|c|}
\hline Sr. & Factors & $\begin{array}{l}\text { Dubai } \\
\text { Custom }\end{array}$ & $\begin{array}{l}\text { Dubai } \\
\text { Police }\end{array}$ & $\begin{array}{l}\text { Dubai } \\
\text { Courts }\end{array}$ & $\begin{array}{l}\text { Emirates } \\
\text { Airline }\end{array}$ & BP & AD \\
\hline 1 & Software and hardware features & 5 & 1 & 2 & 2 & 5 & 5 \\
\hline 2 & Business Intelligence applications & 1 & 3 & 1 & 3 & 6 & 6 \\
\hline 3 & Database and Repositories & 4 & 2 & 4 & 4 & 7 & 7 \\
\hline 4 & Operating System & - & - & - & - & 8 & 8 \\
\hline 5 & Browsers and search engine & 6 & 5 & 5 & 5 & 3 & 4 \\
\hline 6 & Protocols and standards & - & - & - & - & 1 & 1 \\
\hline 7 & Social networking applications & 3 & 6 & 6 & 6 & 2 & 2 \\
\hline 8 & $\begin{array}{l}\text { Tacit knowledge management } \\
\text { and retention }\end{array}$ & 2 & 4 & 3 & 1 & 4 & 3 \\
\hline
\end{tabular}

Weighted Scoring is a strategy for putting a semblance of objectivity into a subjective procedure. It utilizes a reliable rundown of criteria, weighted as per the importance or necessity of the criteria to the association. By summing the weighted values, the item most nearly meeting the criteria could be determined ${ }^{[14]}$.

Participants scored the CSF, in term of weightage \%, based on business priority, strategy, and experience. See Appendix B. The average scores are shown in table 2. 
Table 2: Average weightage score against each factor

\begin{tabular}{|c|c|c|}
\hline \multirow[t]{2}{*}{ Technical Dimensions } & \multicolumn{2}{|c|}{ Average Weight Score (\%) } \\
\hline & $\begin{array}{c}\text { Governmental- } \\
\text { services } \\
\text { organizations }\end{array}$ & $\begin{array}{c}\text { Private - } \\
\text { production } \\
\text { organizations }\end{array}$ \\
\hline $\begin{array}{l}\text { Software and } \\
\text { hardware features }\end{array}$ & $28 \%$ & $8 \%$ \\
\hline $\begin{array}{l}\text { Business Intelligence } \\
\text { applications }\end{array}$ & $21 \%$ & $5 \%$ \\
\hline $\begin{array}{l}\text { Database and } \\
\text { Repositories } \\
\end{array}$ & $16 \%$ & $13 \%$ \\
\hline Operating system & $0 \%$ & $8 \%$ \\
\hline $\begin{array}{l}\text { Browsers \& search } \\
\text { engine }\end{array}$ & $5 \%$ & $15 \%$ \\
\hline $\begin{array}{l}\text { Protocols and } \\
\text { Standards }\end{array}$ & $0 \%$ & $18 \%$ \\
\hline $\begin{array}{l}\text { Social networking } \\
\text { applications }\end{array}$ & $8 \%$ & $23 \%$ \\
\hline $\begin{array}{l}\text { Tacit knowledge } \\
\text { management and } \\
\text { retention. }\end{array}$ & $22 \%$ & $13 \%$ \\
\hline
\end{tabular}

Thus, the interview revealed that these factors are dependent on criteria such as quality, security, maintainability, accessibility, simplicity, etc. In service organizations, the software and hardware feature are strongly dependent on these factors in addition to easy interface adoption. Tacit knowledge management and retention, the second top CSF, depends mainly on search engine capability and essential data storage. For a production organization, the interviews revealed that social networking application is a function of quality, accessibility, and type of data used while database and repositories factors are dependent on quality, security and type of data stored. See appendix C.

\subsubsection{Case study and Lessons learned}

British Petroleum Company KMS - A Case study

BP adopted a KM system in 1996 and the purpose was organizational learning and best practice transfer in oil \& gas upstream. Nowadays, BP has become one of the leaders in the field on knowledge management. BP estimated that $\$ 700$ million was saved in 1998 as result of knowledge sharing ${ }^{[12]}$, and about $\$ 50$ million was saved by leveraging knowledge from different stages of oil \& gas processing ${ }^{[15]}$. Information technology plays an important role in improving the effectiveness of KMS. Although competitors such as Schlumberger relied more on the codification of the information, BP focused on people-oriented approaches to achieve KM objectives. In both cases, IT Management was the main driver of technology and people-based activities.

One of the main challenges BP faced was how to implement KM initiatives successfully. BP experienced difficulties and even failure at the earlier stages on implementation of KM. The main problems encountered covering technical dimensions are as follows:

- Database (data mining and storing): The most problematic area of KM was the application of IT to knowledge storage and database creation to store data and serve as corporate memories for important information such as best practices, technical and managerial performance data, company yellow pages, supplier and customer information data dictionaries, supplier contracts, digital libraries, catalogs, general news, manuals, online training modules, and bibliographic databases. Integrating all this data into one system was problematic for most of the companies ${ }^{[12]}$ As a result, BP started focused first on storing the two (2) main data types which will add value to BP as a business which are project lessons learned, and best practices. The company defined IT requirements for each stage of database collection and storage. See figure 5 .

\begin{tabular}{|c|c|c|}
\hline PHASE OF KM & INFORMATION TECHNOLOGIES AN & Toots \\
\hline Capture and Store & $\begin{array}{l}\text { Electronic Document Management } \\
\text { System (EDMS) Database Management } \\
\text { System (DBMS) }\end{array}$ & \multirow{8}{*}{$\begin{array}{l}\text { Internet and } \\
\text { Intranet }\end{array}$} \\
\hline Search and Retrieve & Information Retrieval & \\
\hline $\begin{array}{l}\text { Send critical } \\
\text { information to } \\
\text { individuals or groups }\end{array}$ & Push/agent, e-mail & \\
\hline $\begin{array}{l}\text { Structure and } \\
\text { Navigate }\end{array}$ & Classification, World Wide Web/HTML & \\
\hline $\begin{array}{l}\text { Share and } \\
\text { Collaborate }\end{array}$ & $\begin{array}{l}\text { Workflow, Groupware, e-learning. } \\
\text { Virtual Communities }\end{array}$ & \\
\hline Synthesize & Data mining, Business Intelligence & \\
\hline $\begin{array}{l}\text { Profile and } \\
\text { Personalize }\end{array}$ & Agents. Portal & \\
\hline $\begin{array}{l}\text { Solve or } \\
\text { Recommend }\end{array}$ & $\begin{array}{l}\text { Case-based reasoning. Rule-based } \\
\text { systems }\end{array}$ & \\
\hline
\end{tabular}

Figure 5: Information technology for Knowledge Management in BP

The main two (2) problems highlighted by BP are as follows: - When numerous documents or alternatives are presented, users have difficulty in knowing which is best. The information being inputted into corporate databases often fails to capture the real insights that were generated during the project.

- Much of the information in corporate databases is out of date. There is a credibility problem for the user. Information in a database that is not linked to a respected individual will not necessarily be trusted ${ }^{[12]}$.

- Software tools $\&$ search engines: selecting the suitable software helps in linking the databases, making them widely accessible. It makes the searching activity easy and fast to navigate at lower cost. BP utilized an Oracle web-based search engine earlier but recently switched to Google search engine in some applications (interview with Mathew, BP IT leader). Schlumberger, on the other hand, is using real time tools to capture and share operations data faster and with more reliability using a web-based system.

- Portals: BP is using personalized applications through which employees and customers can retrieve and share knowledge and documents, display links and calendars, etc. It helps in reducing the inconvenience caused by using multiple applications ${ }^{[12]}$. This has proven to be a successful step in using ITM not only to link people to information but also link people to people which is one of the successful strategies in implementing a KM system effectively, as mentioned by Mathew, BP IT leader.

\section{Dubai Courts}

A visit was done to Dubai Courts to view how they implement a KM system. They use many applications such as manual of services, knowledge portal, and subscribed E-services. Their annual measurement of user opinion about using a knowledge system was $82 \%$ as a level of satisfaction in 2012 and $92 \%$ in 2013. Technology enhances knowledge accessibility and the 
speed of knowledge transfer. Database and intranet are more involved in knowledge management activities. An IT team ensures the security of the system and the departments are responsible for accuracy of data. The challenges they faced were finding ways to determine the experience and convert it to knowledge, and to develop databases linked to each other. Dubai Courts also explained that business intelligence reports were very useful especially when there were similar cases in courts. The recommendation, however, was that knowledge management needs to have a centralized review with decentralized deployments. The research by Dubai school of Government shows a trend towards the focus of knowledge management program in IT. In addition, having a knowledge management system has improved the performance of employees and departments.

\section{Dubai Police}

Dubai Police has a program known as 'Knowledge Manager' which asks for the knowledge that requires managing by Dubai police. The program helps it understand and define different types of knowledge they have such as knowledge gain from customers, cases, and employees. The program was developed and designed in-house and employee knowledge and experience was used in order to establish the database. Many entities within Dubai Government are requesting training and workshop sessions from Dubai Police who has based knowledge \& experience. Dubai Police employees depend on the program for information they need. The challenges faced by them are finding ways to categorize knowledge especially because of security issues. Dubai Police has overcome that problem by giving colors and codes for the level of the case which depends on the grade and position of the employee.

\section{Emirates Airline}

Emirates Airline has a different type of activities such as collaboration tools. These tools allow employees to create a virtual web-based workspace through which they can share information in an electronic environment. Other employees can access and benefit from the previous collaboration which helps them improve services and products. The collaboration also optimizes and improves innovation, problem solving, and decision making. Emirates Airline was successful in establishing a knowledge management system with the support of top management which realizes the return on investment of applying such tools. Today, Emirates Airline is one of the most important airlines in region.

\subsection{Challenges}

- Investment in knowledge management is important especially in the long term.

- Senior management support for investment in knowledge management can be difficult especially if management is more involved in daily operations instead of decision making.

- Organization culture can hold or stop the movement of knowledge management and can prevent employees from using the software or the database involved in development.

- Encouraging employees to use the knowledge system has its impact on employee and their resistance to change or share their tacit knowledge.

- Aligning knowledge management with the organization's strategy is very important.
- Confidential issues may cause some difficulty in sharing knowledge even from employees or management especially in organizations like banks and legal offices.

- Organizations may collect and store the wrong information which may not be important to them.

\section{ETHICS AND HUMAN SUBJECT ISSUES}

- A brief of the research purpose and objective will be given to the selected organizations.

- All survey findings will be treated as confidential data.

\section{RECOMMENDATION FOR FUTURE RESEARCH}

It is recommended that future research focus on developing customized selection criteria for each firm covering the three dimensions of organizational, human and technical aspects.

\section{CONCLUSION \& RECOMMENDATIONS}

Knowledge Management systems are considered new and young in the UAE. A few organizations have implemented them successfully such as Dubai Courts, Dubai Customs, Dubai Police, Emirates Airline, and British petroleum. The adaption of a KM system, however, is still a challenge as many critical success factors need to be considered. The interviewed organizations highlighted different technical dimension CSFs which are included software and hardware features, business intelligence applications, database and repositories, operating system, browsers \& search engine, protocols and standards, social networking applications, tacit knowledge management, and retention. The importance and prioritization of these factors depends on the organization's implementation strategy as well as its business type and focus. In addition, lessons learned were provided during the interviews with the selected organizations. Accordingly, the following recommendations are suggested to overcome the challenges:

- Increase the awareness and profile of knowledge management

- Coach and train employee in organizations

- Implement best practices and lessons learned

- Ensure top management commitment and involvement at an early stage

- Ensure integration between the knowledge management system and other systems within the organization such as excellence model and ISO

- Audit knowledge is very important to ensure high quality of information and data provided

\section{ACKNOWLEDGMENTS}

My thanks to Ayisha Al Marzouqi, Noura Al Khatri, and Noura Al Mutawa who were part of the research team.

\section{REFERENCES}

[1] Nonaka, I., 2009. Perspective-Tacit Knowledge and Knowledge Conversion: Controversy and Advancement in Organizational Knowledge Creation Theory. [Online] Available 
http://pubsonline.informs.org/doi/abs/10.1287/orsc.1080. 0412 [Accessed 27 February 2014].

[2] Lisa Quast, 2012. Why Knowledge Management Is Important To The Success Of Your Company. [Online] Available at: http://www.forbes.com/sites/lisaquast/2012/08/20/whyknowledge-management-is-important-to-the-success-ofyour-company/ [Accessed 28 February 2014].

[3] Mind Tools, 2012. Knowledge Management: Making the Most of Intellectual Assets. [Online] Available at: http://www.mindtools.com/pages/article/newISS_87.htm [Accessed 29 February 2014].

[4] DED. (2012, March 13). Undersecretary of DED Mohamed Omar Abdullah Speech for Knowledge Management Conference - M E 2012. Retrieved from DED: $\quad$ https://ded.abudhabi.ae/en/mediacenter/news/Undersecrtary-DED-Mohamed-OmarAbdullahSpeech-for-Knowledge-ManegmentConference

[5] Accenture. (2014, February 11). Accenture 10-Country Study Finds Singapore, Norway and UAE Lead in Digital Government. Retrieved from Accenture: http://newsroom.accenture.com/news/accenture-10country-study-finds-singapore-norway-and-uae-lead-indigital-government.htm

[6] Alavi M. et al , 2000, Review: Knowledge Management and Knowledge Management Systems: Conceptual Foundations and Research Issues, MIS Quarterly, Vol. 25, No. 1. (Mar., 2001), pp. 107-136.

[7] James A., 2006, Knowledge Management software a selection process, CACCI Journal, Vol. 1, available at : HBMEU, accessed on: $6^{\text {th }}$ march 2014.
[8] Penrose, E.T. (1959). The theory of the growth of the firm. New York: Wiley and Sons.

[9] Peter G., 2001, Predictor of IT support for KM: lesson learnt from low firm in Norway, Knowledge and process Management journal, v(8), page 186-194

[10] Rane V., 2002, Knowledge Management: Initiatives at NMIMS. Paper presented at the MANLIBNET $4^{\text {th }}$ Annual National Convention, April 3 to 5,2002, at National Institute of Financial Management, Faridabad, Available at http://eprints.rclis.org/15272/1/04cali_78.pdf, accessed on: $6^{\text {th }}$ march 2014.

[11] Bock, Wally. 1998 "Knowledge Management 101."A Common Sense Approach to the Digital Age. 16 Dec. 2008.

<http://www.knowledgepoint.com.au/starting_out/Article s/ so_wb001a.html>.

[12] Robert M, 2013, The development of Knowledge Management in the oil and gas industry, Department of management Bocconi school of management, Available at : HBMSU, accessed on: $6^{\text {th }}$ march 2014.

[13] Shabbir. (2010, November 9). Application of Information Technology to Business Management. Retrieved from Go4expert: http://www.go4expert.com/community/applicationinformation-technology-t23814/

[14] Zimmer, D. (2011, January 13). What is the Weighted Scoring Method? . Retrieved from http://terms.ameagle.com/2011/01/david.html

[15] Ambrosio, J. (2000): "Knowledge management mistakes". Computerworld. July 3 http://www.computerworld.com/industrytopics/energy/st ory/0,10801,46693,00.html 